\title{
The temporality of existing
}

\begin{abstract}
Introduction: Aging and dying are part of the intrinsic process to the human being. Concomitantly with increasing longevity, the proximity of individuals to the process of death becomes more evident, which is an inherent condition for the human being. The understanding of temporality, including the finitude and death of the human being, is little discussed among people because of the feelings associated with loss and the perception of their own finitude. Objective: to reflect on aging and finitude, relating three types of narratives, Roth's literary narrative, Elias's sociological narrative and Sacks's autobiographical narrative, these being "Patrimony", "The solitude of the dying" and "Gratitude", respectively.
\end{abstract}

Method: This is a narrative review, with a qualitative approach, that allows the correlation of several productions, with the purpose of identifying recurrent themes, which refer to new perspectives, contributing to the consolidation of knowledge in a given area. The analysis will be carried out based on bibliographical perspective and content analysis.

Result: Five thematic categories related to finitude were emerged during aging: (1) The different facets of aging; (2) The finite process during human aging; (3) The process of caring for aging; (4) Aging vs. Death; (5) The arrival of the end.

Conclusion: Understanding and discussing finitude and death is essential to demystify the taboos and myths that guide them in order to build a society composed of people who understand death as a natural process of life

Keywords: aging, death, review, human being
Volume I Issue $6-2017$

\author{
Dharah Puck Cordeiro Ferreira,' Maria da \\ Conceicao Lafayette de Almeida ${ }^{2}$ \\ 'Departament of Neuropsychiatry and Behavioral Sciences, \\ Pernambuco Federal University of Pernambuco, Brazil \\ ${ }^{2}$ Departament of Gerontology, Pernambuco Federal University \\ of Pernambuco, Brazil
}

Correspondence: Dharah Puck Cordeiro Ferreira, Department of Neuropsychiatry and Behavioral Sciences, Pernambuco Federal University of Pernambuco, Brazil, CEP 50670-90I,Email dharah.puck@hotmail.com

Received: July 01, 2017 | Published: August 08, 2017

\section{Introduction}

Aging and dying are part of the process intrinsic to the human being. However, as a topic of reflection and study, the subject has received little attention. While in ancient times living conditions caused deaths, now considered premature, causing the individual in his 40 s to be seen as "old", today, new parameters have been listed for the definition of the elderly that happens to be described as people with Age 60 or older in developing countries. ${ }^{1}$

Thereby, aging as a social phenomenon has been increasing its participation in the world scenario since the last century, due to the accelerated increase of the elderly population. In the past, this process was observed only in developed countries, but over the years, changes in the aging population and the life expectancy of the world population, like the cure of diseases, the improvement of the quality of life and the advancement Technology, led to changes in the demographic profile of the population in developing countries. In case of Brazil, in 2025 the country will occupy, in the world ranking, the 6th place in the number of elderly, with 32 million people., ${ }^{1,2}$ However, aging also brings a significant increase in chronic-degenerative diseases ${ }^{3}$ which is observed worldwide. Concomitantly with increasing longevity, the proximity of individuals to the process of death becomes more evident, which is an inherent condition for the human being.

Death has always been associated to aging and the elderly, and over time, the narrative about this process has gone through several stages, resulting from culture, knowledge, and individual and collective aspects. According to this sense, the understanding of the finitude process is complex and is directly associated with biological, psychological and social changes. ${ }^{4}$
The understanding of temporality, including finitude and death of the human being, is little discussed among people, due to the feelings associated with loss and the perception of their own finitude. ${ }^{5,6}$ However, changes have been observed in this regard, especially in relation to the experience of the aging process and the experience of the death of people close to them or even their own experience of death. Three books illustrate this argument: "Patrimony," by Philip Roth.7 "The Loneliness of the Dying," by Norbert Elias ${ }^{8}$ And "Gratitude" by Oliver Sacks. ${ }^{9}$

Philip Roth's "Patrimony: A Real Story" is an autobiographical narrative insofar as it relates the author's suffering to the death of his own father, an elderly widower who discovered the presence of a brain tumour. In addition to experiencing his father's aging process, Roth shows his readers the dilemmas he experienced during the stages of illness and the father's struggle against death from his perspective as your son. ${ }^{7}$ In the book "The Solitude of the Dying" by Norbert Elias. ${ }^{8}$ The perspective of death and the act of dying are observed from the point of view of the author, who already exceeds eighty years old when he begins the process of elaborating book, during it is aging process. ${ }^{8}$ Lastly \& Oliver Sacks's ${ }^{9}$ Gratitude is written after the publication of his autobiographical book "Life in Motion" authorized in the moment he enters the operating room to remove a malignant brain tumour. Surviving the surgical intervention and before the repercussion of the published book, he writes, then, Gratitude, during your experince of the aging. In this book, Sacks reveals the great joy of meeting his readers and his life, in a kind of farewell. He dies two weeks after its publication. ${ }^{9}$

In this way, these three distinct narratives share the common experience of aging and finitude. One can say that there is among 
these three authors the "urgency" of revealing the invisibility of aging as Elias does, the suffering of the loss of a loved one as Roth does, or gratitude for life lived as Sacks does. All three are important dimensions for facing the processes in focus. Thus, this study aims to reflect on aging and finitude, relating three types of narratives: Roth's literary narrative, Elias's sociological narrative and Sacks's autobiographical narrative, which are respectively, "Patrimony", "Solitude of the dying" and "Gratitude".

\section{Methods}

This article was prepared as a result of the discipline "Gerontology - Society and Culture" of the Graduate Program in Gerontology, Federal University of Pernambuco/UFPE, Recife, PE, Brazil, 2015. It is a narrative review, with a qualitative approach, that allows the correlation of several productions, with the purpose of identifying recurrent themes, which refer to new perspectives, contributing to the consolidation of knowledge in a given area. In addition, it can provide guidance in training professionals, evidence new ideas and perspectives on death and life. ${ }^{8-11}$

Regarding the works analyzed, two observations need to be made: the first refers to the biographical and autobiographical genre as a relevant material for the research and the second refers to content analysis, as an appropriate research method. The two approaches will be discussed below:

\section{The biographical and autobiographical perspective as a method}

The three books analyzed in this article have a biographical or autobiographical dimension, as shown previously. Philipe Roth merges autobiography with biography in narrating the experience of the death of the father, conjugates in part the biographical dimension from the experience of the father before the death of the mother, and of his own experience before the illness and the process of finitude of the father. Medical procedures, family relations, and grief are all woven into the author's account. And so, it is possible to perceive the two approaches: the biographical (the life of the other) and autobiographical (life itself and experience). ${ }^{7}$

Norbert Elias, in "Solitude of the Dying", although containing a strong sociological dimension, the author makes clear the relation between the individual dimension and the social structure. The text also contains a autobiographical dimension while it is thought from the experience of the Aging process suffered by the author himself. According to it, "death is a problem of the living" and "changes in the course of social development". The action-structure relationship is the fundamental point of the work of this author, who uses his 80year experience, looks at the society in which he lives and brings a reflection where biography and sociology merge pertinently. ${ }^{8}$

Oliver Sacks reports through his autobiography an essay on his farewell, although another book has made this more explicit. Thus, it approached the theme of finitude related to a certain amount of feelings inherent to aging and pathological process. ${ }^{9}$

The validity of biographical and autobiographical data has been studied both in history ${ }^{12}$ As in sociology ${ }^{13,14}$ and anthropology. ${ }^{15}$ In Documents of Life, the biography and autobiography are discussed as research papers as one.

A peculiar and particular style of investigating and understanding the human experience that comes close to the concrete individual, man and woman, accurately highlighting the way in which they express their understanding and interpretation of the world they are experiencing. ${ }^{14}$ The method has been widely discussed in Social Sciences generating controversy, but today it is recognized for the importance it brings to the understanding of the human phenomenon. In this way, the biographical genre has been widely used and has contributed to the perception of the differences and nuances presented by the social reality. ${ }^{13}$

\section{The Content analysis perspective}

The works were submitted to Content Analysis, that allows the emergence of thematic categories, which allow the identification of the nuclei of meaning present in the communication that, after reading the texts, were aggregated through the following steps: pre-analysis, exploration of the Material and treatment of results. ${ }^{16}$

At the first moment, in the pre-analysis, a survey was carried out of the books that dealt with the theme of aging and the process of dying written in different periods and that had a biographical and/or autobiographical approach. After selecting these three books, began the exploration of the material. At this stage the three books were read in full and as the reading was done, the thematic categories began to emerge in the text, which made it possible to list five categories that addressed the main issues inherent to the works. In the third and last stage, the treatment of results, it was possible to organize the information and excerpts extracted from the books within the thematic categories defined in the previous stage.

\section{Results and discussion}

After the Content Analysis, five thematic categories related to finitude during aging were emerged:

I. The different facets of aging

II. The finite process during human aging

III. The process of caring for aging

IV. Aging vs. Death

V. The arrival of the end.

\section{The different facets of aging}

Roth $^{7}$ for example, discusses the redefinition of the relationship of the characters' marriages, in the case of the father and the mother, who, by success, are gradually obliterated - by him, the Father "He had nothing to do and she had everything to do, and it did not work".? The process of aging leads to some changes in the life of each human being, one of these begins when the subject retires. The woman has a facility to insert herself or to continue in the home context, since it is already a place where she is extremely active, especially when it comes to the generation born in the early twentieth century, as in the case of the author's parents. Man, with his activities focused on work outside the home, focused on professional work, with the advent of retirement has greater difficulty adapting to the new reality constituted by the absence of work and greater permanence in the space of the house.

Over the years, couples often come to realize that the relationship has no longer has so many affinities and that tolerance measures are introduced into everyday life as a way of counterbalancing situations of greater antagonism, reducing the quality of being together, like before. $^{7}$ 
Aging ends up being related to decay and years lived. In this context, it is observed as painful for the elderly who are alone and for those who are sick. ${ }^{8}$ Therefore, perceiving yourself elderly is a challenge in today's society, which requires courage and audacity through the difficulties encountered by many people inserted in this phase of life. ${ }^{8}$ There are few who can maintain a rhythm and a "contemporaneity" in relation to life, remaining lucid and active until the moment of death as in the case of Sacks ${ }^{9}$ who finishes writing his last book two weeks before the final match.

Regardless of the variety of behaviors, aging comes with with it several conflicts both for the subject who experiences it, and for the family member or caregiver who accompanies this process as a spectator or mediator. These are difficult times for everyone who needs to approach a given situation. It is, among many aspects, dealing with new dimensions of life, where the absence of physical forces compromises the simpler tasks of everyday life. In addition, the loss of productive capacity, which especially for men are their identity reference. Roth's father's resistance to aging manifests itself through the absence of professional identity and illness. Who is he, in this new reality guided by his son? It is the question that is suggested by Roth.?

For Sacks, who was born at the beginning of the twentieth century, the maintenance of the work capacity as a writer brings a different dimension to this process, since it continues to relate to the world through it. The difference in behaviour can be understood as arising from the changes that are taking place in health care, from the use of new technologies and new habits of routine, like practice of exercises, sports and intellectual occupations as it is possible to perceive Through the writing of the author, being possible to bring another facet to think about the aging.

\section{The process of finitude during human aging}

Death has always been perceived as a paradigm for humans, although knowledge about the thematic is the result of problems, which experience of death may vary in each society. ${ }^{8}$ Experiencing the loss of the spouse usually becomes painful because the partner expects to experience the process of finitude before the loved one. However, when surprised, this process becomes more painful, and the experienced mourning can be extended for months. ${ }^{7}$ The death of the other brings the reflection of the very condition of mortality to which the human being is subjected. ${ }^{8}$ The feeling of soul poverty stemming from the loss of a loved one is expressed by Herman Roth as a result of his long life with his partner and his shared life for many years.

On the other hand, the exclusion of death in today's society makes it harder to observe these phenomena in a more natural way. The feeling of discomfort experienced by the living in the face of the presence of the dead means that one does not have "available" words to express perplexity. The distance from death and dying causes a loss of the meaning of dead bodies and burial, about which one does not know what can or should be said.

\section{The process of caring for aging}

The family caregiver during their care journey ends up fixing their idea in physical objects that alleviate their suffering, or bring some symbolic representation of the loved one, that causes that the same is perpetuated in their memories. This fact is evident when the son of Herman Roth states that he wishes to keep the list of doubts of the father about the disease and the beard mug due to the personal value intrinsic to these objects.
The process of acceptance that it will not be possible to have the loved one for the rest of your life brings up questions pertaining to finitude. With this, this process is being built over the course of life, of the years, with the highlight of this construction during aging. ${ }^{7}$

There is no way to change the cycle of life and its natural processes, no matter how much there is a relentless search for methods that can prolong life, this search is vain and boring. It is with these perspectives that family members will have to deal in the process of existence now without the presence of the loved one. Build with significant objects the absence of your loved one. According to Roth when losing a loved one "half or more of our lives are gone".

In Roth, the caretaker is the family, or he is, the son. In Elias ${ }^{8}$ the family is referred to as a social group inserted in a context that partially minimizes the existence of death. Here, the analysis deals with society as a larger whole and it is the structure rather than the agency that comes to be referred to. They are observations on the conception and social importance of death that is part of the analysis he performed. ${ }^{8}$ Elias turns to analyzing the experience of dying by punctuating the differences between the extended family and the nuclear family. It deals with the isolation of the aging process that separates or "splits" the family ties, which mean the separation of the elderly from normal life, increasing the "feeling of loneliness".

Sacks perspective does not address the caregiver dimension. His account is more concerned with his productive life, his work, his relationship with his readers. Gratitude is a book where the author punctuates aspects of life from the perspective of a positive balance. The pains, the death itself are there, are possibly the starting point of the book, but it is the positive balance that occupies the narrative of this writer. ${ }^{9}$

\section{Aging vs. death}

There are many ways to deal with death, even the acceptance that everyone will experience the death process, so there is an end to all, independent of the beliefs that are cultivated throughout life. From this, the idea of another life after death can also contribute to the difficult construction of death in society, that is, if there is an afterlife, one does not think about death, but about the life that will come, as conclusion. $^{8}$

The health-disease process can be experienced before the finitude and even related to it, as in the case of Elias when questioning the extent to which his father could face surgery and his recovery at 86 years of age, which gave rise to an idea "Intolerable" in this context." Therefore, many individuals become ill and grow old, a process in which they gradually result in their death. ${ }^{8}$

The elderly can use coping strategies to ward off the health problem when it focuses on the "dead, dying, dead and friends who would be better off dead" be the best alternative ahead to a complex health-disease process. On the other hand, one tries to avoid the idea of death, by means of an unshakeable faith in one's own immortality, making the existing anxieties arising from this idea bearable. ${ }^{8}$ However, the construction of the health-disease process can lead to the creation of doubts and uncertainties. Thus, it contributes to the difficulty of accepting the clinical picture, as well as the prognosis. ${ }^{7}$ It is worth emphasizing that the more complex the disease, the more difficult it will be to accept it, and the construction of this process, both by the elderly affected by the disease, and by their relative. During this stage, there may be 
the lack of spirit to perform any activity, and even to think / reflect on oneself and life. ${ }^{7}$

Hence, there will be a moment in which the subject will be confronted with reality. At this moment, there will be a need to position oneself its existence, family and health-disease process. ${ }^{7}$ Therefore, understanding the process of dying is essential in order to deal clearly with one's existence. And therefore adjust life and behaviour with others arising from the finitude experienced by all. ${ }^{8}$

Therefore, the way in which each individual experiences the process of dying is directly related to the goals traced and reached during his life. Thus, the value and meaning that each person attributes to his life, through the realization or frustration that allows the understanding of the process of dying differently. ${ }^{8}$

However, being alive represents its construction as a person, and its essence based on its accumulated memories during the long years of its existence. ${ }^{7}$ The farewell of life can be the continuation of this stage, being glimpsed in the best possible way for each individual. ${ }^{8}$

\section{The arrival of the end}

At this moment the first question that arises is: how to be prepared for the arrival of this much-feared death? Although it is a natural process, the human being still has difficulty accepting it due to the abyss that it will cause. Therefore, the individual ceases to be physically present in this society. And, this was not always easy to accept and understand. Sometimes society is wondering what would be the best place to die, at home or in the hospital. Near or far from the people we love? And, what could be described as "good death"?It is now possible to live during your old age in your own home, in a geriatric home, or in a long-term stay institution. After the death of his wife Herman Roth went to look for an apartment in a geriatric home, because his son worried with the fact the same power to die of solitude. ${ }^{7}$

As far as a "good death" is concerned, Sacks can be considered the holder of this, insofar as he remained active until his last breath of life, regardless of having experienced a pathological process. Feeling satisfied with the gift of life he wrote his book as a way of thanking him for his life and experiences. ${ }^{9}$ Soon, he lived in his house and maintained his activities in the same way as in the course of aging.

A change of perspective regarding death was described by Elias, considering that in previous centuries death was observed as a daily spectacle and familiar. Thus, it became hidden behind the scenes of social life, making it possible for this process to be experienced in the hospital environment, away from the family environment. ${ }^{8}$

Thus, death ceased to be a topic of discussion, as it was previously and began to create a distance from society and the process of death/ dying. Although the cover-up of death is an ancient process in human consciousness, the transformation took place in the form of this being carried out, being hidden even from the children allied to the permanent self-control and individualization social process. ${ }^{8}$

It is observed that death is the final step of a natural process, that no matter how much there is a search and a postponement of death, it is known that one day they will all arrive there, however delayed. ${ }^{8}$ The great secret of life is to learn and understand all its stages, which can take a lifetime to accomplish this construction and even if there is no comprehension of its internality.

\section{Conclusion}

Aging concretes the process of finitude in a solid, cold and fast way, which is often hidden for years in the heart of human beings. During this process the human being is clearly confronted with this idea. The pain produced by the death can not be left aside, much less despised, trying to give a more pleasant appearance to this process. However, it must be built in parallel with the process of mourning, which is part of the essence of the human being, and should not be seen as something excluded from the human being and society. Therefore, understanding and discussing about finitude and death is essential to demystify the taboos and myths that guide them, in order to build a society composed of people who understand death as a natural process of life.

\section{Acknowledgements}

None.

\section{Conflict of interest}

Authors declare there is no conflict of interest in composing this manuscript.

\section{References}

1. Organização Mundial de Saúde. Envelhecimento ativo: uma política de saúde. Organização Pan-Americana da Saúde, Brasil. 2006.

2. Luzardo AR, Gorini MIP, Silva APSS. Características de idosos com doença de Alzheimer e seus cuidadores: uma série de casos em um serviço de neurogeriatria. Texto contexto enferm. 2006;15(4):587-594.

3. Reyes PF, Shi J. Dementias: etiologies and differential diagnoses. Barrow Quarterly. 2006;22(1):4-8.

4. Lopes R. Os velhos ainda precisam ser "Indignos"? In: Corte B, Mercadante EF, Arcuri IG, editors. Complex (idade), Velhice Envelhecimento, Brasil; 2005.

5. Schramm FR. Morte e finitude em nossa sociedade: implicações no ensino dos cuidados paliativos. Rev Bras Cancerol. 2002;48(1):17-20.

6. Rego S, Palácios M. A finitude humana e a saúde pública. Cad Saúde Púb. 2006;22(8):1755-1760.

7. Roth P. Patrimônio: uma história real. Tradução: Beth Vieira. Siciliano, São Paulo, Brazil; 1991.

8. Elias N. A solidão dos moribundos. Tradução: Plínio Dentzien. Rio de Janeiro. 2001;14(1):107.

9. Sacks O, Gratidão. Companhia das letras, São Paulo, Brasil; 2015.

10. Rocha EAC. A pesquisa em Educação Infantil no Brasil: trajetória recente e perspectiva de consolidação de uma pedagogia da educação infantil. Florianópolis: UFSC, Centro de Ciências da Educação, Núcleo de Publicações. 1999;23:219-223.

11. Noronha DP, Ferreira SMSP. Revisões de literatura. In: Campello BSVC, Cendón BV, Kremer JM, editors. Fontes de informação para pesquisadores e profissionais. Belo Horizonte: UFMG. 2000;191-198.

12. Thompson P, Samuel R. The myths we live by. Routledge, London, UK; 1990.

13. Bertaux D. From metodological monopoly to pluralism in the sociology of social mobility. In: Dex S, Editor. Life and work history analyses. qualitative and quantitative developments. Routledge, London, UK; 1991. 
14. Plumer K. Documents of life. Unwin Hyman Ltd, London, UK; 1983.

16. Bardin L. Análise de conteúdo. Lisboa: Edições. 2011;70:229.

15. Okely J, Callaway H. Anthropology and Autobiography. Routledge, London, UK; 1992. 